\title{
O PROUNI NO GOVERNO LULA E O JOGO POLÍTICO EM TORNO DO ACESSO AO ENSINO SUPERIOR
}

\author{
Cristina Helena Almeida de Carvalho*
}

\begin{abstract}
RESUMO: O objetivo deste texto é compreender a relação complexa e dinâmica da política pública para o ensino superior no governo Lula, no que tange ao Projeto Universidade para Todos (PROUNI) e sua articulação com a política fiscal e o financiamento por meio da renúncia tributária. Pretende-se ainda analisar as condiçóes de acesso aos estudantes pobres e questionar o programa como política pública de democratização. Neste contexto, o respaldo da sociedade civil em busca do diploma de graduação tem sido acompanhado da pressão de associações representativas do segmento privado. A tentativa de regular o sistema e obter retorno da renúncia fiscal concedida às filantrópicas foi restringida à medida que a evolução do texto legal foi na direção do afrouxamento do aparato estatal. Conclui-se que o empecilho à democratização está na escassez de vagas públicas e gratuitas. Nesse momento, as medidas voltadas à expansão do segmento federal ainda são insuficientes para reverter este quadro perverso.
\end{abstract}

Palavras-chave: Ensino superior. Renúncia fiscal. Financiamento. Prouni. Democratização do acesso.

The PROUNI IN LULA's ADMINISTRATION AND THE POLITICAL GAME AROUND ACCESS TO HIGHER EDUCATION

ABSTRACT: This paper aims at understanding the complex and dynamic relationships between the public policy for higher education in Lula's administration, in what regards the Project University for All (PROUNI), and its connection with fiscal policy and financing by way of tributary renouncement. It also intends to analyze the conditions of access of poor students and discuss the program as a

* Doutoranda em Economia Social e do Trabalho e mestre em Economia pelo Instituto de Economia da Universidade Estadual de Campinas (UNICAMP); bolsista do CNPq. E-mail: crishele@eco.unicamp.br

Agradeço às sugestôes, comentários e críticas do professor Luiz Antonio Cunha.

Educ. Soc., Campinas, vol. 27, n. 96 - Especial, p. 979-1000, out. 2006

Disponível em <http://www.cedes.unicamp.br> 
democratizing public policy. In this context, the civil society approval in search of graduation certificate allied to the pressure of private representatives associations. The attempt to regulate the system and obtain return on the fiscal renouncement allowed to philanthropic institutions was restricted by the legal text, which evolved toward the slackening of the state framework. The author concludes that the obstacle to democratization is the lack of public and free places. To date, the measures aimed at increasing the federal sector are still insufficient to revert this perverse situation.

Key words: Higher education. Fiscal renouncement. Financing. PROUNI. Democratizing access.

\section{Introdução}

$\mathrm{O}$

texto pretende entender o Programa Universidade para Todos $(\text { PROUNI })^{1}$ - como ação estatal prioritária do governo Lula - articulado à operação da política fiscal, bem como ao mecanismo indireto de renúncia fiscal às Instituiçôes de Ensino Superior privadas (IES). Objetiva-se ainda analisar as condições de acesso das camadas mais pobres ao ensino superior e questionar o programa como política pública de democratização.

A concessão de bolsas de estudos integrais e parciais para estudantes de ensino superior em troca de renúncia fiscal surge acompanhada pela retórica de justiça social e de inclusão das camadas sociais menos favorecidas, cujo principal indicador é o baixo contingente de alunos de 18 a 24 anos que freqüenta o ensino superior. $\mathrm{O}$ evidente respaldo da sociedade civil em busca do diploma de graduação é acompanhado pela pressão das associações representativas do segmento privado.

No entanto, é importante contextualizar o programa no bojo do ambiente econômico mais amplo e nas mudanças ocorridas na forma de operação da política fiscal, que alteraram os espaços de financiamento das políticas públicas. A renúncia fiscal torna-se novamente relevante como mecanismo de financiamento da política pública para a educação superior privada.

$\mathrm{O}$ artigo está estruturado em três seções, além da introdução e da conclusão. Na primeira parte, pretende-se entender o PROUNI inserido na nova lógica das finanças públicas e do financiamento indireto direcionado aos estabelecimentos privados de educação superior. Na se- 
gunda parte, a intenção é esquadrinhar o jogo político em torno do programa ao longo de sua formulação, seus principais atores e interesses envolvidos. Nesta seção, investiga-se o perfil institucional das IES participantes do programa no município de São Paulo. Observa-se, de forma parcial, até que ponto a implementação difere do esperado por seus formuladores. Por fim, o texto procura analisar o programa como política pública de acesso às camadas mais pobres e discutir sua efetividade social.

\section{A nova lógica das finanças públicas e a renúncia fiscal}

Para compreender os moldes de construção do PROUNI, torna-se relevante, em primeiro lugar, conhecer o contexto econômico no qual este programa se insere, tanto no que diz respeito à nova lógica das finanças públicas, quanto às mudanças na legislação da renúncia fiscal direcionadas às instituições de ensino superior privadas.

No primeiro ponto, a discussão exige retroceder no tempo para entender as alteraçôes ocorridas na gestão da política fiscal, a partir dos anos de 1990, e as dificuldades em ampliar os gastos públicos. Na visão convencional, o indicador basilar da situação fiscal era o déficit público. O controle deste déficit ocupava lugar central na política macroeconômica. Não é por outra razão que os organismos multilaterais sempre defendiam seu corte como medida inicial da política de ajustamento.

Esta questão alterou-se com a abertura dos mercados financeiros, o crescente fluxo de investimentos e a volatilidade dos capitais presente na década. A ampla mobilidade do capital levou a corrente econômica dominante a dar outro rumo à avaliação da política fiscal e a exigir esforço adicional por parte dos países em desenvolvimento para se credenciarem como candidatos a receptores dos novos fluxos de capitais. A questão fiscal ganhou lugar central no arranjo da política macroeconômica, sobretudo, a dívida pública tornou-se um dos ativos usados na valorização do capital financeiro.

O resultado fiscal convencional baseado no controle do déficit público deixou de ser a referência principal e a sustentabilidade da dívida passou a ser o novo indicador. Este permitiu incorporar na análise o problema da avaliação do comportamento esperado das finanças públicas em cenários prováveis. A partir do momento em que esta idéia 
tornou-se dominante, deixou de ser suficiente o país demonstrar que goza de boa situação fiscal. É preciso que o mercado acredite que, no cenário esperado, não haverá risco de calote na dívida. Em outras palavras, os investidores precisam ter confiança que a dívida seja sustentável. $^{2}$

Esta interpretação da política fiscal foi definitivamente implantada no Brasil, após o acordo com o FMI, em 1998. O órgão passou a exigir do governo de Fernando Henrique Cardoso um superávit primário capaz de assegurar a sustentabilidade da dívida, quaisquer que fossem a taxa de câmbio e a taxa de juros incidentes sobre o estoque da dívida pública. A existência de taxa de juros reais elevada e a instabilidade cambial, ao lado da medíocre evolução do PIB, não deixaram alternativa senão promover constantes aumentos do superávit primário.

No governo Lula, a elevação do superávit primário se deu por meio de duas medidas. Em primeiro lugar, houve o aumento da carga tributária (30\% do PIB, em 1998, para 35\% em 2003). Em segundo lugar, ocorreram importantes cortes nos gastos públicos. A adoção da âncora fiscal implica a definição, à priori, do superávit primário. Assim, o valor dos gastos passa a se ajustar ao comportamento da receita orçamentária, o que acarreta cortes de despesas, sobretudo em custeio e capital. Explicam-se assim o arrocho salarial, o corte das verbas de custeio com saúde, educação e outros, bem como a redução dos gastos com investimentos. Não é de se surpreender que os investimentos públicos sejam os mais baixos da história recente do país e, após as sucessivas privatizações, perderam o papel que tinham como articuladores das condiçōes de crescimento.

No que tange ao segundo aspecto, a política de incentivos e isenções fiscais para apoiar a atuação privada remonta ao final dos anos de 1960, quando o governo militar valeu-se desses instrumentos para impulsionar o projeto de desenvolvimento nacional, beneficiando ampla gama de setores em diferentes áreas. Em relação ao ensino superior, o mecanismo de renúncia fiscal tornou-se fator central no financiamento do segmento privado. ${ }^{3}$ A Lei n. 5.172/66, que instituiu o Código Tributário Nacional, em concordância com a CF/67, determinava a nãoincidência de impostos sobre a renda, o patrimônio e os serviços dos estabelecimentos de ensino de qualquer natureza. ${ }^{4} \mathrm{Em}$ outras palavras, as organizaçôes privadas de ensino superior gozaram do privilégio, desde a sua criação, de imunidade fiscal, não recolhendo aos cofres públicos a receita tributária devida. 
Esse instrumento de financiamento indireto foi fundamental para o crescimento intensivo dos estabelecimentos na prosperidade econômica e, principalmente, garantiu a continuidade da atividade no período de crise, por amortecer o impacto sobre custos e despesas inerentes à prestação de serviços.

Apesar de existirem requisitos restritivos para as entidades educacionais terem acesso à imunidade fiscal, na prática, grande parte usufruiu deste benefício. A instituição de ensino ou mantenedora, na forma de associação civil ou fundação, considerada como entidade sem fins lucrativos, poderia receber por seus produtos e serviços. Porém, deveria reinvestir o superávit na manutenção e expansão das atividades educacionais.

Em linhas gerais, a imunidade refere-se ao Imposto sobre a Propriedade Predial e Territorial Urbana (IPTU), o Imposto sobre Serviços de Qualquer Natureza (ISSQN), ambos de competência do poder municipal, além do Imposto sobre a Renda e Proventos de Qualquer Natureza (IRPJ) e do Imposto sobre a Propriedade Territorial Rural (para imóveis localizados em zonas rurais), ambos de competência da União. ${ }^{5}$ As filantrópicas, além da imunidade, gozam da isenção da cota patronal da Previdência Social. Em contrapartida, exige-se a destinação de 20\% da receita bruta em gratuidade.

Para o Programa de Integração Social (PIS) há uma forma diferenciada de cobrança entre as instituiçóes com fins lucrativos, sem fins lucrativos e as filantrópicas. As primeiras recolhem sobre o faturamento ou receita bruta. Para as duas últimas, a cobrança do tributo incide sobre a folha de pagamento.

A Contribuição Social sobre o Lucro Líquido (CSLL) destina-se ao financiamento da seguridade social e a Contribuição Social para Financiamento da Seguridade Social (COFINS) às despesas com atividadesfim das áreas de saúde, previdência e assistência social, instituídas a partir da CF/88, que atingiram as IES particulares. A CSLL baseia-se no valor do resultado do exercício, antes da provisão para o imposto de renda, sendo que as instituições sem fins lucrativos e filantrópicas são isentas da cobrança. Já a COFINS incide sobre o faturamento mensal e apenas essas últimas estão sujeitas à isenção.

Os impactos microeconômicos da renúncia fiscal repercutiram no processo de expansão a partir dos anos de 1970. A imunidade do IPTU 
permitiu à instituição adquirir um maior número de imóveis, para alojar mais cursos e alunos, sem ônus tributário sobre as despesas operacionais, servindo inclusive como estímulo à ampliação do ativo imobilizado. A imunidade do ISSQN e a isenção da COFINS estimularam o aumento de matrículas, já que não há ônus tributário sobre a ampliação da prestação de serviços. A imunidade do Imposto de Renda e a isenção da CSLL possibilitaram a continuidade da atividade educacional e evidenciaram a saúde financeira da instituição. $\mathrm{O}$ resultado positivo viabilizava o financiamento bancário, o auxílio externo e a obtenção de recursos de agências de fomento.

Para a entidade filantrópica, a isenção do INSS permitiu ampliar a contratação de pessoal docente e administrativo. O crescimento da folha de pagamento não teve impacto tributário significativo nos custos operacionais, enquanto o recolhimento do PIS apresentou peso muito pequeno sobre a folha salarial.

Nos anos de 1990, houve significativa alteração legislativa, estabelecida pelo artigo 20 da LDB/96. A medida sofreu severas críticas das associaçōes de classe que defendem os interesses privados. Até então, todos os estabelecimentos usufruíram imunidade tributária sobre a renda, os serviços e o patrimônio. A partir deste momento, as instituiçóes passaram a ser classificadas em privadas lucrativas e sem fins lucrativos (confessionais, comunitárias e filantrópicas).

A mudança legislativa permitiu ampliar a arrecadação da União e dos municípios, mas reduziu, de forma significativa, a rentabilidade de grande parte dos estabelecimentos privados de ensino superior, que deixaram de se beneficiar diretamente de recursos públicos e indiretamente da renúncia fiscal, como previa o artigo 213 da Constituição Federal de 1988.

\section{O jogo político em torno do PROUNI}

O caminho privado de expansão de matrículas, cursos e instituições, que foi tão intenso nos anos de 1970 e teve um novo surto expansivo nos anos de 1990, principalmente entre 1998 e 2002, resultou na criação de um número excessivo de vagas que, segundo informaçōes recentes do INEP, é superior ao número de formandos no ensino médio. ${ }^{6}$ Embora a demanda potencial por ensino superior não 
se restrinja ao número de concluintes do ensino médio, é muito difícil estimar o número de pleiteantes. Neste cálculo, inclui-se não apenas parte dos recém-formados, como também aqueles que retornam tardiamente aos bancos escolares. ${ }^{7}$ Este fenômeno dá indícios de que o segmento privado disponibiliza um contingente de vagas não procuradas pelos estudantes.

Esta situação gerou um quadro de incerteza no setor, ainda mais quando se leva em conta o grau de inadimplência/desistência. ${ }^{8}$ A queda nos rendimentos reais e o nível elevado de desemprego dificultam a sustentação dos gastos com as mensalidades pelos assalariados.

Diante do cenário de deterioração social, o Programa de Financiamento Estudantil (FIES), antigo Programa de Crédito Educativo, que transferia recursos a fundo perdido às IES privadas, não tem sido suficiente para reverter a tendência de esgotamento do segmento particular.

Neste contexto, o Programa Universidade para Todos (ProunI) surge com o discurso de justiça social, tendo como público-alvo os estudantes carentes, cujos critérios de elegibilidade são a renda per capita familiar e o estudo em escolas públicas ou privadas na condição de bolsistas. Além disso, o programa estabelece, obrigatoriamente, que parte das bolsas deverá ser direcionada a ações afirmativas aos portadores de deficiência e aos negros e indígenas. A formação de professores de ensino básico da rede pública também consta como prioridade. A intenção é a melhoria na qualificação do magistério, com possíveis impactos positivos na qualidade da aprendizagem dos alunos da educação básica.

Tais medidas corroboram com os interesses de parte da sociedade civil, dos movimentos sociais em prol das açôes afirmativas, bem como dos egressos do ensino médio público, por não se considerarem uma demanda potencial às instituições públicas frente às barreiras impostas pelos exames vestibulares.

A demanda reprimida, que busca no programa o acesso ao ensino superior, pode ser observada no impressionante número de visitas à página do Ministério da Educação à época da seleção para o programa, cuja solução foi desmembrá-la em duas. No segundo semestre de 2006, houve 200.792 inscrições e apenas $23 \%$ de bolsas de estudos concedidas, ou seja, 47.059, e, no estado de São Paulo, a proporção foi ainda menor, 17\%, 51.313 inscritos para apenas 8.884 bolsas. Outro indício importante foi o crescimento do número de inscritos no ENEM, que 
é o requisito indispensável para participação do programa. De acordo com o INEP, em 2004 foram 1.547.222 e em 2005 foram 3.004.491, um acréscimo de $94 \%$.

Algumas figuras públicas, tais como cantores e sindicalistas, cuja imagem está associada ao "homem do povo", realizaram propagandas em jornais, revistas e em canais televisivos em prol da importância e do papel de democratização do PROUNI. Vale ressaltar que a Central Única dos Trabalhadores (CUT), um dos principais aliados do atual governo, por meio de seu presidente, mostrou-se simpatizante ao programa em manifestação nos meios de comunicação, alegando ter, afinal, chegado a hora do trabalhador ter acesso ao ensino superior (Marinho, 2005). ${ }^{9}$

A legitimidade social do programa encontra ressonância na pressão das associações representativas dos interesses do segmento particular, justificada pelo alto grau de vagas ociosas. ${ }^{10} \mathrm{O}$ PROUNI surge como excelente oportunidade de fuga para frente para as instituições ameaçadas pelo peso das vagas excessivas.

Durante a tramitação no Congresso Nacional, houve atuação efetiva dos atores representantes das IES particulares. ${ }^{11}$ Estes se manifestaram publicamente, após as modificaçōes introduzidas pela Medida Provisória na forma de adesão antecipada. Matérias pagas, em apoio ao programa, foram veiculadas nos principais jornais de circulação do país. ${ }^{12}$

Quando se observa a formulação da política pública, de forma mais detalhada, por meio da evolução do Projeto de Lei, da Medida Provisória até a Lei do PROUNI ${ }^{13}$ e o decreto que a regulamentou, é possível afirmar que as alterações no texto legal conduziram à flexibilização de requisitos e sanções e à redução da contrapartida das instituições particulares. ${ }^{14}$ A redação final do documento refletiu o jogo político, no qual o MEC teve de ceder e acomodar os interesses privados, e estes atores não foram plenamente atendidos.

No entanto, os atores privados foram atingidos pela ação estatal, tanto pelas regras de composição de bolsas como pela mesma isenção dos tributos federais. Esta situação gerou interesse diverso em participar do programa, uma vez que uma parte das IES já está isenta ou imune a alguns deles.

Quanto à primeira questão, no caso das instituiçôes lucrativas e sem fins lucrativos e não-beneficentes, as regras são bem mais flexíveis e a adesão é voluntária. A barganha dá-se na concessão de bolsas integrais ou na 
redução, de forma significativa, das bolsas integrais tendo como parâmetro para a concessão de bolsas parciais $(50 \%$ e $25 \%)$ a receita bruta.

Em 2005, essas instituições deveriam destinar uma bolsa integral para nove alunos pagantes ou bolsas parciais até $10 \%$ da receita bruta. A partir de 2006, o documento é bastante generoso para ambas. A relação de estudantes pagantes por bolsas concedidas é ampliada e o comprometimento da receita bruta é reduzido: uma bolsa integral para 10,7 alunos pagantes ou, de forma alternativa, conceder uma bolsa integral para 22 estudantes, com quantidades adicionais de bolsas parciais $(50 \% \mathrm{e}$ $25 \%$ ) até atingir $8,5 \%$ da receita bruta. Acrescenta-se, a isso, duas sutilezas constantes da Lei n. 11.096 de 13.01 .05 e do Decreto n. 5.493 de 18.07.05, que a regulamenta, para o cálculo do número de bolsas integrais. No decreto de 2004, constava que o total de estudantes pagantes nâo levaria em consideração os bolsistas parciais do programa. Já no decreto de 2005, os bolsistas são considerados como alunos pagantes. $\mathrm{Na}$ lei, passou a existir ainda a possibilidade dos trabalhadores (e dependentes) da própria instituição participarem do programa, limitados a $10 \%$ das bolsas concedidas. ${ }^{15}$

No caso das filantrópicas, as regras são bem mais rigorosas. A adesão ao programa e a concessão de bolsas integrais são obrigatórias. As demais modalidades de gratuidade (bolsas parciais e programas de assistência social) podem ser usadas para compor o total de $20 \%$ da receita bruta. Este percentual é o requisito mínimo que caracteriza a natureza jurídica deste tipo de instituição.

A partir da publicação da Medida Provisória, essas instituições têm declarado que estariam dispostas a deixar o status de entidades de assistência social para se tornarem instituições com fins lucrativos. Vale ressaltar, no entanto, que aquelas que perderam tal status por não cumprirem o percentual mínimo de gratuidade exigido poderão, com a adesão ao PROUNI, solicitar a revisão dos processos e possível restabelecimento do certificado junto ao Conselho Nacional de Assistência Social (CNAS) e, posteriormente, requerer ao Ministério da Previdência Social o retorno da isenção das contribuições. Em outras palavras, a participação no programa permitiria retomar as condiçôes anteriores à cassação, com cancelamento das dívidas existentes.

Um segundo ponto importante é a homogeneização proposta pelo programa na isenção de tributos. Para melhor compreender essa 
questão, a Tabela 1 compara as instituições com fins lucrativos, as sem fins lucrativos (confessionais e comunitárias) e as entidades filantrópicas, antes e depois da adesão ao programa. Discriminam-se as bases de cálculos e as alíquotas dos principais tributos federais para cada categoria de estabelecimento particular.

Tabela 1

Alíquotas e Base de Cálculo dos Tributos Federais por Categoria de IES

\begin{tabular}{|c|c|c|c|c|c|c|}
\hline \multirow{3}{*}{ Tributos } & \multirow{2}{*}{\multicolumn{2}{|c|}{ Com fins lucrativos }} & \multicolumn{4}{|c|}{ Sem fins lucrativos } \\
\hline & & & \multicolumn{2}{|c|}{ Confessional / Comunitária } & \multicolumn{2}{|c|}{ Filantrópica } \\
\hline & Atual & PROUNI & Atual & PROUNI & Atual & PROUNI \\
\hline IRPJ & $25 \% \times$ lucro & - & - & - & - & - \\
\hline CSLL & $9 \% \times$ lucro & - & - & - & - & - \\
\hline COFINS & $7,6 \% \times$ receita & - & $3 \% \mathrm{x}$ receita & - & - & - \\
\hline PIS & $1,65 \%$ x receita & - & $1 \% \mathrm{x}$ folha & - & $1 \% \times$ folha & - \\
\hline $\begin{array}{l}\text { INSS } \\
\text { (patronal) }\end{array}$ & $20 \% \times$ folha & $20 \% \times$ folha & $20 \% \times$ folha & $20 \% \mathrm{x}$ folha & - & - \\
\hline
\end{tabular}

Fonte: Carvalho e Lopreato (2005)

É possível perceber que as instituiçôes mais beneficiadas são aquelas com fins lucrativos, já que ficam isentas, a partir da adesão, de praticamente todos os tributos federais que recolhiam.

As instituiçōes sem fins lucrativos deixam de recolher a COFINS e o PIS. O impacto sobre a rentabilidade deve ser importante, uma vez que a isenção da COFINs estimula o aumento de matrículas e, conseqüentemente, o crescimento da receita operacional bruta, já que não há ônus tributário sobre o incremento na prestação de serviços. A isenção do PIS tem impacto muito reduzido sobre a folha salarial.

As entidades filantrópicas apenas se beneficiam da isenção do PIS, cujo ônus fiscal é pouco representativo. Novamente, é possível compreender suas alegações em se tornarem filantrópicas. A troca de imunidade por isenção, por dez anos renováveis por iguais períodos, não traz prejuízos significativos e os tributos municipais podem ser barganhados com os poderes locais. O INSS patronal, de acordo com o explicitado na legislação do PROUNI, pode ser suavemente parcelado nos cinco primeiros anos.

Nesse ponto, a concepção do programa fere o artigo 213 da Constituição Federal de 1988, como bem lembra Pinto (2004), uma vez que a Carta Magna não permite a destinação de recursos públicos para 
instituições com fins lucrativos e apenas admite bolsas de estudo para o ensino fundamental e médio e, neste caso, para as instituições sem fins lucrativos.

Outra questão polêmica foi estabelecer na MP a competência exclusiva da fiscalização ao Ministério da Educação. Como este órgão não dispõe de quadro técnico especializado, haveria dificuldades no controle contábil/fiscal, ao passo que tal medida desautorizava e impedia o trabalho desenvolvido, nos últimos anos, de combate à sonegação do Ministério de Estado da Previdência Social e da Receita Federal. Os dois órgãos federais alertaram para o perigo de tal iniciativa. ${ }^{16}$ Com a promulgação da Lei, a redação foi alterada, a partir da manifestação destes atores burocráticos, para constar que o MEC será responsável, apenas, por verificar o cumprimento das exigências e informar aos órgãos competentes a situação de cada entidade.

O valor da renúncia fiscal depende do nível de adesão e do tipo de instituição participante do programa. Em 2005, 1.142 estabelecimentos particulares aderiram ao programa; em 2006, são 1.232. Isto representa um aumento de $8 \%$. As particulares, em sentido estrito, que representam em 2004, segundo o INEP, cerca de $78 \%$ dos estabelecimentos e $54 \%$ das matrículas privadas, tendem a aderir em maior número. Contudo, se uma parcela das filantrópicas deixar o status de entidade de assistência social, apesar dos obstáculos legais para tal, poderá haver um aumento da arrecadação previdenciária. De acordo com um levantamento divulgado pela Receita Federal, em 2005 a renúncia fiscal foi bem menor ( $\mathrm{R}$ \$ 105 milhões) que a projeção da União ( $\mathrm{R}$ \$ 197 milhões). Neste ano, foram oferecidas 112 mil bolsas, que representam um custo anual por estudante de R $\$ 937,50 .{ }^{17}$

É importante reforçar o alerta dos pesquisadores Catani, Hey e Gilioli (2006), quanto à falta de informações desagregadas e de séries históricas do PROUNI, que inviabilizam pesquisas mais aprofundadas. Não se encontram disponíveis: total de bolsas por IES, a relação total das IES que aderiram ao programa, o detalhamento dos cursos disponíveis e/ou escolhidos, o perfil dos estudantes (dados econômicos e sociais), taxas de evasão e desempenho acadêmico dos beneficiários.

No momento, é possível quantificar apenas o número de bolsas integrais/parciais por região, estado e município, constante das Estatísticas do PROUNI no site do MEC. A Tabela 2 mostra a evolução entre 2005 
e 2006 da implementação, para o Brasil, estado de São Paulo e a cidade de São Paulo.

As bolsas no estado de São Paulo representavam 32\% do total em 2005 e, em 2006, houve uma queda relativa para $27 \%$. Isto ocorreu porque o aumento de $24 \%$ do total de bolsas no Brasil foi bem superior aos $3 \%$ no estado. Já a participação da cidade no estado foi ampliada de $37 \%$ para $40 \%$, cujo acréscimo de bolsas foi de $13 \%$. O ponto comum ao país, ao estado e ao município foi o crescimento das bolsas integrais, que representam entre $60 \%$ a $70 \%$ do total, contrariando a suposta maior disponibilidade de bolsas parciais. Tal fato pode ter ocorrido, em parte, devido à baixa renda familiar dos demandantes do programa.

Tabela 2

Evolução na oferta de Bolsas de Estudo - PROUNI

\begin{tabular}{l|r|r|r|r|r|r|r|r|r}
\hline & \multicolumn{3}{|c|}{ Bolsas 2005 } & \multicolumn{3}{c|}{ Bolsas 2006 } & \multicolumn{2}{c}{ Taxas de Crescimento } \\
\hline & Integrais & Parciais & \multicolumn{1}{|c|}{ Total } & Integrais & Parciais & \multicolumn{1}{c}{ Total } & Integrais & Parciais & Total \\
\hline Brasil & 71.905 & 40.370 & 112.275 & 98.698 & 39.970 & 138.668 & $37 \%$ & $-1 \%$ & $24 \%$ \\
Estado de São Paulo & 21.713 & 13.939 & 35.652 & 25.768 & 11.007 & 36.775 & $19 \%$ & $-21 \%$ & $3 \%$ \\
Estado/Brasil & $30 \%$ & $35 \%$ & $32 \%$ & $26 \%$ & $28 \%$ & $27 \%$ & & & \\
Cidade de São Paulo & 8.658 & 4.437 & 13.095 & 9.810 & 4.990 & 14.800 & $13 \%$ & $12 \%$ & $13 \%$ \\
Cidade/Estado & $40 \%$ & $32 \%$ & $37 \%$ & $38 \%$ & $45 \%$ & $40 \%$ & & & \\
\hline
\end{tabular}

Fonte: PROUNI/MEC

A fim de observar o perfil institucional de adesão ao programa, compatibilizou-se o banco do endereço das IES participantes do PROUNI ao Cadastro da Educação Superior do INEP, para identificar quais as instituiçôes participantes do programa, no segundo semestre de 2006, na cidade de São Paulo. A escolha baseou-se nos seguintes critérios: o estado de São Paulo ter participação privada (85\%) bem superior à média nacional (70\%); a cidade mais rica da Federação abrigar o segmento privado mais antigo do país; e o município corresponder à cerca de $30 \%$ das IES particulares do estado.

No segundo semestre de 2006, há registro de 52 instituições participantes, o que representa $34 \%$ dos estabelecimentos localizados no município (153). Apesar da cidade ter uma rede antiga e tradicional, verificou-se que mais de 60\% foram criadas a partir de 1994 e a grande maioria entre 1999 e 2002 em faculdades de tecnologia. Por esse motivo, apenas 50\% foram submetidas à avaliação de cursos, cujas 
notas foram, em geral, baixas nos centros universitários e com grande variação nas universidades.

\section{Tabela 3}

IES privadas na cidade de São Paulo segundo organização acadêmica

\begin{tabular}{l|c|c|c|c|c}
\hline & Total & Participação & PROUNI & Participação & PROUNI/total \\
\hline Faculdades & 83 & $54 \%$ & 19 & $37 \%$ & $23 \%$ \\
Faculdades de tecnologia & 22 & $14 \%$ & 12 & $23 \%$ & $55 \%$ \\
Faculdades Integradas & 11 & $7 \%$ & 0 & $0 \%$ & $0 \%$ \\
Instituto Superior & 12 & $8 \%$ & 2 & $4 \%$ & $17 \%$ \\
Centros Universitários & 13 & $8 \%$ & 7 & $13 \%$ & $54 \%$ \\
Universidades & 12 & $8 \%$ & 12 & $23 \%$ & $100 \%$ \\
Total & 153 & $100 \%$ & 52 & $100 \%$ & $34 \%$ \\
\hline
\end{tabular}

Fonte: PROUNI/MEC

Quanto à organização acadêmica, a Tabela 3 mostra que $75 \%$ das IES são classificadas como faculdades (faculdades, faculdades de tecnologia e faculdades integradas) e $8 \%$ como institutos superiores, centros universitários e universidades. Das faculdades, o maior percentual de adesão localiza-se nas tecnológicas. No caso dos centros universitários, 54\% são participantes do programa. Já nas universidades, a adesão é plena.

\section{Tabela 4}

IES privadas na cidade de São Paulo segundo categoria administrativa

\begin{tabular}{l|c|c|c|c|c}
\hline & Total & Participação & PROUNI & Participação & PROUNI/total \\
\hline Particular Sentido Estrito & 121 & $79 \%$ & 42 & $81 \%$ & $35 \%$ \\
Comunitária & 0 & $0 \%$ & 0 & $0 \%$ & - \\
Confessional & 3 & $2 \%$ & 0 & $0 \%$ & $0 \%$ \\
Confessional - Filantrópica & 5 & $3 \%$ & 3 & $6 \%$ & $60 \%$ \\
Filantrópica & 24 & $16 \%$ & 7 & $13 \%$ & $29 \%$ \\
Total & 153 & $100 \%$ & 52 & $100 \%$ & $34 \%$ \\
\hline
\end{tabular}

Fonte: PROUNI/MEC

No que tange à categoria administrativa, os dados da Tabela 4 revelam que a grande maioria (79\%) é de particulares em sentido estrito, cuja adesão voluntária foi de apenas 35\%. Não há comunitárias, apenas oito são confessionais, sendo cinco também filantrópicas. As instituições filantrópicas (19\%), que, em tese, são obrigadas a participar do programa, apresentaram participação aquém do esperado. 
A conclusão, pelo menos para cidade de São Paulo, que pode ser tomada como um caso exemplar da implementação do PROUNI, é de que a participação de todas as universidades (seis filantrópicas e seis lucrativas) independente de sua categoria administrativa e pode estar relacionada ao elevado índice de inadimplência e vagas ociosas, face à estrutura dos estabelecimentos. No entanto, o grau de adesão é bem inferior ao esperado, tanto das lucrativas, que se beneficiam da renúncia fiscal recuperada, como das filantrópicas, que não teriam escolha e seriam os alvos preferenciais da política pública para justificar a imunidade e a isenção mantidas ao longo dos últimos quarenta anos.

\section{O PROUNI e o acesso ao ensino superior}

Os dados sobre o perfil dos estudantes no ensino superior revelam que a democratização do ensino é bastante complexa no Brasil, diante da brutal desigualdade de renda entre as famílias e a reduzida parcela do ensino gratuito e de qualidade.

Apesar da expansão excepcional de vagas, em 2004, a escolaridade líquida da população de 18 a 24 anos é de $10,4 \%$, sistema classificado internacionalmente como de elites. Deve-se levar em conta ainda que cerca de $60 \%$ dos matriculados estavam nessa faixa etária. Este quadro é explicado, por um lado, pelo retorno aos bancos escolares de profissionais em busca do diploma de nível superior como credencial de qualificação e promoção funcional e, por outro, pelo atraso e pelo abandono (temporário ou definitivo) escolar que fazem parte da realidade nacional.

Quando se desagregam os dados, por renda (familiar per capita em salários mínimos) da população na faixa etária de 18 a 24 anos, observa-se que a proporção de alunos aumenta conforme as faixas de renda mais elevadas. Nas faixas acima de três salários mínimos, a proporção de estudantes é superior a $35 \%$, ao passo que, com a renda de até um s.m., apenas $1,5 \%$ freqüenta a graduação. Torna-se relevante salientar que $86 \%$ da população nessa faixa etária enquadra-se nos níveis de renda de menos de três s.m, público-alvo do PROUNI.

A situação é mais grave, pois a maior parte dessa população encontra-se em atraso escolar e, dessa forma, não pode ser atingida por qualquer política de estímulo à entrada no sistema. De acordo com os dados da PNAD (1999): 46\% abandonaram os estudos antes de com- 
pletar o ensino médio; $10 \%$ estudam, mas com distorção de idade-série; $19 \%$ terminaram o ensino médio e pararam de estudar; e apenas $25 \%$ freqüentam o ensino médio ou superior (Castro, 2005).

O financiamento estudantil dado pelo FIES deixa de ser uma alternativa viável aos alunos de baixa renda, face à defasagem entre a taxa de juros do empréstimo e a taxa de crescimento da renda do recém-formado, combinada ao aumento do desemprego na população com diploma de nível superior. Ademais, como os requisitos são mais rigorosos, a fim de evitar a inadimplência (a exigência de fiador e a possibilidade de financiamento de apenas $50 \%$ do valor da mensalidade), grande parte da população de baixa renda não é atingida por tal política pública.

A expansão do ensino superior dos anos de 1990, que acelerou o processo de privatização em curso desde a Reforma Universitária de 1968, está diante de um impasse: Como ampliar o acesso da população de baixa renda, que concluiu a educação básica, e da classe média, que foi rebaixada socialmente e, em grande parte, perdeu empregos ou sobrevive no mercado informal?

Os dados revelam a tendência ao esgotamento do crescimento pela via privada manifestada pela assimetria entre a oferta de vagas, que cresceu $16,8 \%$ entre 2003 e 2004 , e o número de ingressantes de apenas $2 \%$ no período. $\mathrm{O}$ percentual de vagas não preenchidas nas instituições privadas está, segundo o INEP, em 49,5\% em 2004 e a relação candidato/vaga, em 1,3, ao passo que na rede pública este indicador é superior a 10. Resta questionar se o PROUNI será capaz de reverter este cenário. Para isso, é necessário aguardar os resultados do Censo do Ensino Superior de 2005.

De acordo com Corbucci (2004, p. 698), o programa "constitui iniciativa, ainda que tímida, de redistribuição indireta da renda, ao transferir recursos de isenção fiscal a estratos populacionais mais pobres, já que tais recursos, caso fossem arrecadados, não beneficiariam necessariamente esses grupos sociais". Mancebo (2004b, p. 86) alerta que,

(...) longe de resolver ou de corrigir a distribuição desigual dos bens educacionais, a privatização promovida pelo programa tende a aprofundar as condiçôes históricas de discriminação e de negação do direito à educação superior a que são submetidos os setores populares. A alocação dos estudantes pobres nas instituiçōes particulares cristalizará mais ainda a dinâmica de segmentação e diferenciação no sistema escolar, destinando escolas 
academicamente superiores para os que passarem nos vestibulares das instituições públicas e escolas academicamente mais fracas, salvo exceções, para os pobres.

No entanto, é importante ponderar que não permitir o acréscimo da isenção fiscal às IES privadas possibilitaria um maior bolo de recursos constitucionalmente garantidos ao ensino público; em outras palavras, reduzindo o financiamento indireto via renúncia fiscal em troca do acréscimo no financiamento ao segmento federal.

Ainda é importante levar em conta que, ao contrário do senso comum, diversos estudos vêm demonstrando que, apesar da brutal desigualdade de acesso ao ensino superior entre os ricos e os pobres, há maior participação das camadas mais pobres nas instituições públicas que nas suas congêneres particulares, materializada na menor participação dos 10\% mais ricos, na maior parcela dos 50\% mais pobres, na maior proporção de estudantes negros ou pardos e na menor renda média mensal familiar. ${ }^{18}$

Diante do quadro social e educacional deletérios, cabe questionar a efetividade de tal programa, uma vez que as camadas de baixa renda não necessitam apenas de gratuidade integral ou parcial para estudar, mas de condições que apenas as instituiçôes públicas, ainda, podem oferecer, como: transporte, moradia estudantil, alimentação subsidiada, assistência médica disponível nos hospitais universitários e bolsas de trabalho e pesquisa.

Nesse sentido, o MEC concede, a partir de 2006, bolsa de permanência de $\mathrm{R} \$ 300,00$ para as despesas de transporte, alimentação e material didático aos beneficiários que estudam em tempo integral. A iniciativa é importante, mas insuficiente, não apenas em termos monetários, mas por seu grau de abrangência, uma vez que pretenderia atingir 4.500 alunos, cerca de 2\% do total de bolsistas de 203.516, nos anos de 2005 e 2006.

Parece apropriada a afirmação de Catani e Gilioli (2005), segundo a qual o PROUNI deve promover uma política pública de acesso, mas não de permanência e conclusão do curso, orientando-se por uma concepção assistencialista, nos moldes das recomendações do Banco Mundial, que oferece benefícios e não direitos aos egressos do ensino médio público. $\mathrm{Na}$ concessão de bolsas de estudos parciais de $50 \%$, caso os beneficiários não possam pagar a parte que lhes cabe, não é permitida 
a matrícula no semestre ou no ano seguinte, o que tende a aumentar a possibilidade de evasão. ${ }^{19}$

Segundo informações obtidas no site do MEC, das 112 mil matrículas efetuadas em 2005, cerca de 95 mil estudantes permanecem, cuja taxa de evasão é de $15 \%$, que pode estar associada tanto às dificuldades financeiras do aluno como à insatisfação com a instituição e/ou curso freqüentado. Torna-se importante comparar este indicador com a taxa de evasão dos estudantes das IES privadas que não fazem parte do PROUNI no período.

\section{Considerações finais}

Coerente com a nova lógica das finanças públicas, o diagnóstico do aumento de vagas ociosas - no segmento privado -, combinado à procura por ensino superior das camadas de baixa renda, fundamentou a proposta do MEC de estatização de vagas nas instituições particulares em troca da renúncia fiscal. Este trabalho sugere que o Programa Universidade para Todos deve operar, à semelhança do PROER para o sistema bancário, ${ }^{20}$ em benefício da recuperação financeira das instituições particulares endividadas e com alto grau de desistência e de inadimplência. As instituições mais beneficiadas parecem ser as lucrativas, que não apenas estão submetidas às regras mais flexíveis, como também obtêm maior ganho relativo em renúncia fiscal, em troca de um número reduzido de bolsas de estudos.

A tentativa de regular o segmento privado e obter retorno da renúncia fiscal concedida às filantrópicas foi restringida, à medida que a evolução do texto legal foi na direção do afrouxamento do aparato estatal. A inexistência de sanções mais severas pelo descumprimento das regras estabelecidas, combinada ao lapso temporal para avaliação dos cursos, estimula comportamentos oportunistas por parte de instituições de qualidade duvidosa. ${ }^{21}$

No entanto, é importante lembrar que a questão do acesso à educação superior permanece em aberto. Considerando-se sua legitimidade social, o programa pode trazer o benefício simbólico do diploma àqueles que conseguirem permanecer no sistema e, talvez, uma chance real de ascensão social para poucos que estudaram no seleto grupo de instituiçóes privadas de qualidade. Mas, para a maioria, cuja porta de 
entrada encontra-se em estabelecimentos lucrativos e com pouca tradição no setor educacional, o programa pode ser apenas uma ilusão e/ou uma promessa não cumprida. Ademais, a gratuidade integral ou parcial para estudar não é suficiente para seus beneficiários, os quais necessitam de assistência estudantil que apenas as instituiçôes públicas ainda podem oferecer.

O empecilho à massificação do ensino superior brasileiro não está na ausência de vagas para o ingresso no sistema, mas na escassez de vagas públicas e gratuitas. Estas são insuficientes e inadequadas diante do perfil dos estudantes que concluem o ensino médio. Deste contingente, $63 \%$ estudam em escolas públicas no período noturno.

O dado revela uma grave desarticulação do fluxo escolar entre os dois níveis educacionais, uma vez que a educação superior pública concentra menos de $30 \%$ das matrículas, em sua maior parte, nos cursos diurnos. Este fato constitui-se um dos principais gargalos para ampliar o acesso dos estratos sociais mais pobres.

A perspectiva de mudança da política pública, em contradição à nova lógica das finanças públicas, reside na expansão em curso do segmento federal de ensino superior (universidades, campis e quadro docente e funcional), combinada às ações afirmativas direcionadas à população estudantil oriunda da escola pública e aos grupos étnicos historicamente desfavorecidos. No momento, estas medidas ainda são bastante incipientes e insuficientes para reverter esse quadro perverso.

Recebido em agosto de 2006 e aprovado em setembro de 2006.

\section{Notas}

1. Apesar do título do programa referir-se ao termo Universidade, o PROUNI destina-se a qualquer tipo de instituição de ensino superior privada.

2. O conceito de dívida líquida engloba o total da dívida interna e externa federal, estadual e municipal, reduzida dos haveres dos três níveis de governo. Sobre finanças públicas, consultar Lopreato (2005).

3. Esta tese encontra-se em Carvalho (2002). Sobre os propósitos da renúncia fiscal no regime militar e no PROUNI, ver Carvalho (2005).

4. A Constituição Federal de 1946 já previa a renúncia fiscal direcionada ao sistema educacional, mas esse mecanismo tornou-se mais visível no período militar a partir do boom das instituições privadas. 
5. Um maior detalhamento sobre os impostos e contribuições sociais que serão mencionados a seguir pode ser encontrado em Carvalho (2002) e Carvalho e Lopreato (2005).

6. Conforme o Censo da Educação Superior divulgado pelo INEP, foram em torno de 2 milhôes de vagas nos processos seletivos em 2003 e 1,88 milhões de estudantes que concluíram o ensino médio. No entanto, o número de inscritos chegou a cerca de 4,9 milhōes.

7. Constam desta lista aqueles que prestam vestibular para um segundo curso de graduação e as diversas inscrições de uma mesma pessoa para cursos ou instituições distintas.

8. Aqueles que demandam ensino superior percebem que a qualidade das instituiçôes privadas é bastante diversificada e que os serviços educacionais oferecidos não são homogêneos. Instituiçôes tradicionais e aquelas cujas estratégias de marketing são mais agressivas, provavelmente terão menor incerteza quanto ao preenchimento das vagas oferecidas do que as demais.

9. Chama a atenção o número de vagas disponíveis nas cidades de Santo André (1.462 em 2005 e apenas 714 em 2006) e São Bernardo do Campo (1.289 em 2005 e 1.958 em 2006). Este fato demonstra a elevada demanda, inclusive, de grande parte dos trabalhadores sindicalizados filiados à CUT e a ausência de instituições públicas. Além da compra de vagas nas IES privadas, o MEC criou a Universidade Federal do ABC, em Santo André, que terá a primeira turma com 500 vagas, 250 no diurno e 250 no noturno. A UNIFESP também chegou na região, em Diadema e Guarulhos.

10. Em geral, as IEs privadas disponibilizam um número excessivo de vagas no primeiro ano, a fim de compensar financeiramente a desistência acentuada nos anos seguintes. Contudo, as taxas de evasão e de inadimplência tendem a crescer face à excessiva concorrência na oferta e ao baixo poder aquisitivo da demanda.

11. O texto da MP foi alterado na Câmara Federal por proposta dos deputados do PFL e apoio do PSDB e por pressão dos atores políticos representantes das instituições privadas no Congresso Nacional. As instituiçōes com ou sem fins lucrativos teriam que destinar apenas $7 \%$ de vagas para o programa. O ministro da Educação, Tarso Genro, afirmou que foi decisiva neste processo a participação do reitor da Universidade Paulista (UNIP). Ver, a este respeito, GOVERNO tenta derrubar alteração no PROUNI (2004). Esta afirmação parece ter fundamento, uma vez que esta instituição é uma das maiores do país e seu proprietário vem influenciando, há anos, a política de ensino superior, tanto no Congresso Nacional como no Conselho Nacional de Educação.

12. Consultar o programa Universidade para Todos - PROUNi e a inclusão social (2004). Ainda assim, no site da ABMES consta uma carta da instituição assinada pelas principais representantes das particulares, que foi endereçada ao então ministro da Educação, Tarso Genro, onde o critério de cálculo para concessão de bolsas deveria ser o número de alunos pagantes matriculados no $2^{\circ}$ ano, face à brutal desistência, em torno de $30 \%$, ocorrida no primeiro ano dos cursos de graduação privados (ABMES, 2006).

13. A evolução do corpo legislativo do Programa entre o Projeto de Lei, da Medida Provisória n. 213 de 10/09/2004 até a Lei n. 11.096 de 13/01/2005 encontra-se mais detalhada em Carvalho e Lopreato (2005) e Catani e Gilioli (2005).

14. O Projeto de Lei estabelecia uma multa de, no máximo, $1 \%$ do faturamento anual do exercício anterior à data da infração para a instituição de ensino superior particular que descumprir as regras do PROUNI. A partir da MP e na Lei, deixa de constar sanção pecuniária para o desrespeito às regras do programa.

15. Em investida mais recente das IES privadas, na revista mensal Educação Superior, publicada pelo Sindicato das Entidades Mantenedoras de Estabelecimentos de Ensino Superior no

Educ. Soc., Campinas, vol. 27, n. 96 - Especial, p. 979-1000, out. 2006

Disponível em <http://www.cedes.unicamp.br> 
O PROUNI no governo Lula e o jogo político em torno do acesso ao ensino superior

Estado de São Paulo, de abril deste ano, há uma matéria sobre o PROUNI, na qual se critica a pouca abrangência do programa e se afirma que a proposta das entidades é a renegociação dos débitos previdenciários e fiscais em até 240 meses em troca de bolsas do Prouni. Segundo estimativas do autor do artigo, atendida essa condição, poderia haver um "PROUNI 2", que geraria mais de um milhão de bolsas. Ver, a este respeito, Goitia (2006).

16. Ver, a este respeito, Souza (2004).

17. Este valor parece muito pequeno face às despesas das IES privadas, mesmo para aquelas cujos cursos concentram-se nas áreas de humanas e sociais (ProunI sai mais barato que o previsto, 2006).

18. Dentre os estudos que corroboram com esta conclusão, encontram-se os trabalhos de Sampaio, Limongi e Torres (2000), Schwatzmann apud Corbucci (2004), Pinto (2004) e Mancebo (2004a), baseados nos bancos de dados da Pesquisa Nacional por Amostra de Domićlí (PNAD) realizada pelo IBGE e do questionário socioeconômico respondido em conjunto com o Exame Nacional de Cursos ("Provão"). No primeiro trabalho, a pesquisa foi bem mais ampla e analisou o perfil dos jovens de 18 a 24 anos e as características dos formandos de 1999. Conclui-se que as chances de ingresso na educação superior estão relacionadas com a renda familiar e com o nível de escolaridade dos pais. No entanto, para os poucos com o perfil diferenciado que conseguem ter acesso, os estabelecimentos públicos constituem uma alternativa para a obtenção do diploma de graduação. Outra conclusão interessante é que ainda que seja reduzida a participação de formandos negros e pardos, independentemente do curso, a maior participação encontra-se nos estabelecimentos públicos.

19. Em que pese a existência de poucos estudos sobre o desempenho dos estudantes bolsistas e a ausência de informaçóes do MEC, vale registrar a pesquisa realizada pela PUC de Minas Gerais, na qual se mostra que as taxas de reprovação, tanto por desempenho como por frequiência, foram, em média, bem mais baixas que seus colegas, ao passo que a taxa de evasão apresentou pequena redução (BOLSISTAS do PROUNI têm bom desempenho na PUC Minas, 2006).

20. O Programa de Estímulo à Reestruturação do Sistema Financeiro Nacional (PROER), instituído pela Medida Provisória n. 1.179/95, teve como objetivo prestar socorro financeiro aos bancos privados para evitar que ocorresse uma crise de confiança no sistema bancário, com conseqüências sobre o conjunto da sociedade. O problema no segmento privado de ensino superior não teria a mesma dimensão. Portanto, é duvidosa a pertinência de uma ação semelhante à do Banco Central.

21. Conforme tem sido veiculado na imprensa, parece que alguns cursos que não passaram nas avaliaçōes do "Provão" e do SINAES fazem parte da lista de instituiçōes selecionadas para participar do PROUNI. Diante da pressão dos meios de comunicação, o MEC instituiu, em março deste ano, a Comissão Nacional de Acompanhamento e Controle Social do programa (CONAP).

Referências bibliográficas

ASSOCIAÇÃO BRASILEIRA DE MANTENEDORAS DO ENSINO SUPERIOR (ABMES). Carta ao Ministro da Educação. Disponível em: <http://www.abmes.org.br>. Acesso em: 9 ago. 2006. 
BOLSISTAS do PROUNI têm bom desempenho na PUC Minas. 2006. Disponível em: <http://www.universiabrasil.net/materia/materia.jsp?materia $=10300>$. Acesso em: 9 maio 2006.

BRASIL. Lei n. 5.172, de 25 de outubro de 1966. In: Oliveira, J. (Org.). Código Tributário Nacional. 18. ed. São Paulo: Saraiva, 1989.

BRASIL. Ministério da Educação. Disponível em: <http://www.mec.gov.br > Acesso em: nov. 2004/ fev. 2005.

BRASIL. Ministério da Educação. PROUNI sai mais barato que o previsto. Disponível em: <http://portal.mec.gov.br/index.php?noticias=1>. Acesso em: 10 jun. 2006.

BRASIL. Ministério da Educação. Instituto Nacional de Estudos e Pesquisas Educacionais (INEP) Estatísticas do ensino superior. Disponível em: <http://www.inep.gov.br>. Acesso em: dez. 2004/mar. 2005; jun. 2006.

BRASIL. Senado Federal. Leis, Decretos e Portarias. Disponível em: <http://www.senado.gov.br>. Acesso em: nov. 2004 a fev. 2005.

CARVALHO, C.H.A. Reforma universitária e os mecanismos de incentivo à expansão do ensino superior privado no Brasil. (1964-1984). 2002. 171f. Dissertação (Mestrado) - Instituto de Economia, Universidade Estadual de Campinas, Campinas.

CARVALHO, C.H.A. Política de ensino superior e renúncia fiscal: da reforma universitária de 1968 ao PROUNI. In: REUNIÃO ANUAL DA ASSOCIAÇĀO NACIONAL DE PÓS-GRADUAÇÃO E PESQUISA EM EDUCAÇÃO, 28., 2005, Caxambú. Anais... Caxambú: ANPED, 2005.

CARVALHO, C.H.A.; LOPREATO, F.L.C. Finanças públicas, renúncia fiscal e o PROUNI no governo Lula. Impulso, Piracicaba, v. 16, n. 40, p. 93-104, maio/ago. 2005.

CASTRO, M.H.G. et al. Ensino superior: perfil da graduação e da pósgraduação. In: LANDI, F.R. (Coord.). Indicadores de ciência, tecnologia e inovação em São Paulo: 2004. São Paulo: FAPESP, 2005. v. 1, p.3-5; v. 2 p. 3-32.

CATANI, A.M.; GILIOLI, R.S.P. O PROUNI na encruzilhada: entre a cidadania e a privatização. Linhas Críticas, Brasília, DF, v. 11, n. 20, p. 55-68, jan./jun. 2005.

Educ. Soc., Campinas, vol. 27, n. 96 - Especial, p. 979-1000, out. 2006 
CATANI, A.M.; HEY, A.P.; GILIOLI, R.S.P. PROUNI: democratização do acesso às instituições de ensino superior? 2006. (mimeo.).

CORBUCCI, P.R. Financiamento e democratização do acesso à educação superior no Brasil: da deserção do Estado ao projeto de reforma. Educação \& Sociedade, Campinas, v. 25, n. 88, p. 677-702, out. 2004.

GOITIA, V. Caminhos para inclusão social. Ensino superior, São Paulo, v. 8 , n. 91 , abr. 2006.

GOVERNO tenta derrubar alteração no Prouni. Folha de S. Paulo, São Paulo, 03 dez. 2004. Cotidiano, caderno C, p. 4.

LOPREATO, F.L.C. Finanças públicas: a marcha continua. Política Econômica em Foco, Campinas, n. 5, p. 103-117, 2004/2005. Disponível em: <http://www.eco.unicamp.br>. Acesso em: 5 maio 2005.

MANCEBO, D. Reforma universitária: reflexōes sobre a privatização e a mercantilização do conhecimento. Educação \& Sociedade, Campinas, v. 25 , n. 88 , p. $845-866$, out. 2004 a.

MANCEBO, D. "Universidade para todos": a privatização em questão. Pro-Posiçôes, Campinas, v. 15, n. 3, p. 75-90, set./dez. $2004 \mathrm{~b}$.

MARINHO, L. PROUNI é passo para democratizar o ensino. Folha de S. Paulo, São Paulo, 28 fev. 2005. Opinião, p. 3.

PINTO, J.M.R. O acesso à educação superior no Brasil. Educação \& Sociedade, Campinas, v. 25, n. 88, p. 727-756, out. 2004.

O PROGRAMA Universidade para Todos: PROUNI e a inclusão social. Folha de S. Paulo, São Paulo, 01 out. 2004. Opinião, p. 3.

SAMPAIO. H.; LIMONGI, F.; TORRES, H. Eqüidade e heterogeneidade no ensino superior brasileiro. Brasília, DF: INEP, 2000.

SOUZA, J. Medida provisória do PROUNI cria a "promamata". Folha de S. Paulo, São Paulo, Brasil, p. 13, 26 set. 2004. 